\title{
Specific and quantitative detection of Human polyomaviruses BKPyV and JCPyV in the healthy Pakistani population
}

\author{
Iqra Hussain ${ }^{1}$, Fareeda Tasneem², Muhammed Umer ${ }^{3}$, Ayesha Pervaiz ${ }^{1}$, Muslim Raza ${ }^{4}$,
} Muhammad Imran Arshad ${ }^{5}$ and Naveed Shahzad ${ }^{1 *}$

\begin{abstract}
Background: The BK Polyomavirus (BKPyV) and JC polyomavirus (JCPyV) infections are widespread in human population and have been associated with severe kidney and brain disorders, respectively. The viruses remain latent primarily in reno-urinary tract, reactivating only in case of a compromised immune system. The seroepidemiology and molecular prevalence of BKPyV and JCPyV have been widely studied both in healthy and immunocompromised patients worldwide. However, data regarding the prevalence of these viruses in the immunocompetent or apparently healthy Pakistani population is lacking. Herein, we present the first ever report on quantitative prevalence of BKPyV and JCPyV in the peripheral blood of a randomly selected cohort of healthy Pakistani population.
\end{abstract}

Methods: A total of 266 whole blood samples were examined. The subjects were divided into three age groups: $\leq 25$ years (young), $26-50$ years (middle) and $\geq 51$ years (elder). Absolute real time PCR assay was designed to quantify the BKPyV and JCPyV viral copy numbers in the range of $10^{6}$ to $10^{\circ}$ copies $/ \mathrm{mL}$.

Results: Overall, BKPyV was detected in 27.1\% (72/266) individuals while JCPyV in 11.6\% (31/266) indicating significant difference $(p<0.005)$ in the distribution of these two viruses. The prevalence of BKPyV significantly decreased from $51 \%$ (49/96) in young age group to $8.2 \%(7 / 85)$ in eldest age group. Whereas, JCPyV positivity rate slightly increased from 8. $3 \%(8 / 96)$ in young age group to $11.8 \%(10 / 85)$ in elder age group. The median viral load was calculated as $6.2 \log$ and 3.38 log copies/mL of blood for BKPyV and JCPyV, respectively. Notably, no significant difference in viral load of either of the subtypes was found between different age groups.

Conclusion: The current study provides an important baseline data on the prevalence and viral load of circulating BKPyV and JCPyV in Pakistani population. The prevalence and viral load of BKPyV was comparatively higher than JCPyV. The prevalence of BKPyV significantly decreased with increase in age while JCPyV positivity rate slightly increased with increasing age. Viral load of both BKPyV and JCPyV was not correlated with the individual ages.

Keywords: BKPyV, JCPyV, qPCR, Healthy blood, Pakistan

\section{Background}

The first two human polyomaviruses BK polyomavirus $(\mathrm{BKPyV})$ and JC polyomavirus (JCPyV) were described in 1971 by Gardner et al. and Padget et al. in two separate reports respectively $[1,2]$. Since then there has been considerable research to unravel the molecular structure, pathogenesis, and biology of various polyomaviruses. With the recent discoveries of many new species, there has been

\footnotetext{
* Correspondence: hnaveed.shahzad@gmail.com

'School of Biological Sciences, University of the Punjab, Lahore, Pakistan

Full list of author information is available at the end of the article
}

a heightened focus on polyomavirus research. Primary $\mathrm{BKPyV}$ and JCPyV infections are usually asymptomatic or tend to be mild respiratory or gastrointestinal tract infection $[3,4]$. Immunocompetent individuals can be infected with these two viruses at early ages, where the viruses may remain latent in various body organs like the reno-urinary tract and lymphoid tissues [5]. The destabilization of immune system due to the organ transplant or other immunocompromising conditions like severe acquired immunodeficiency (AIDS) may lead to the reactivation 
of BKPyV and JCPyV probably due to the deficiency of cytotoxic and helper $\mathrm{T}$ cells that are no longer available to keep a check on the virions [6]. The reactivation of $\mathrm{BKPyV}$ and JCPyV in immunocompromised individuals has been linked with several human malignancies. The $\mathrm{BKPyV}$ is reported to cause hemorrhagic cystitis and polyomavirus associated nephropathy (PVAN) while JCPyV is linked with Progressive Multifocal Leukoencephalopathy (PML) [7].

The BKPyV and JCPyV have circular double stranded DNA genome of approximately $5 \mathrm{~kb}$ which is organized into three regions named as the early, the late and the middle regions $[8,9]$. The early region of $\mathrm{BKPyV}$ transcribes three transforming proteins called $\mathrm{T}$ antigens; $\mathrm{LT}$ antigen, ST antigen, and Truncated $\mathrm{T}$ antigen, whereas JCPyV early region encodes five $\mathrm{T}$ antigens; $\mathrm{LT}$ antigen, ST antigen, T'135, T'136 and T'165 antigens [10, 11]. The late region of both BKPyV and JCPyV encodes four proteins VP1, VP2, VP3 and agnoprotein. Likewise, the non-coding control region (NCCR) of both viruses is arranged in between early and late region having origin of replication [11].

The upper urinary tract is primary site of productive and replicative BKPyV infection. However, antigens of $\mathrm{BKPyV}$ can also be detected in many other tissues, almost in every cell type of respiratory tract, skin, bone, brain, colon and in the blood $[12,13]$. On the other hand, JCPyV has a restricted tissue tropism range due to interaction with specific host cell surface $\alpha 2$, 6-linked sialic acid receptors [14]. Oligodendrocytes and astrocytes of brain, kidney cells, lung epithelial cells and B lymphocytes display this receptor and are the sites of primary infection and reactivation [15]. Both of these viruses have also been demonstrated to remain latent in the peripheral mononuclear cells (PBMCs) particularly lymphocytes of healthy immunocompetent individuals [16-19]. The presence of BKPyV in PBMCs is thought to be associated with the ability of virus to manipulate host immune system so as to facilitate its spread from site of primary infection to the site of persistence [20]. However, it is not clear whether JCPyV remain latent in CNS and reactivates upon immunosuppression or it persists in blood from where it can transport to CNS after reactivation $[21,22]$.

Different seroprevalence studies as indicator of primary infection conducted around the globe have revealed that antibodies against BKPyV and JCPyV are present in 60 $80 \%$ of healthy individuals [23]. Despite being ubiquitous, $\mathrm{PyV}$ infection in immunocompetent individuals does not do any harm to them that is of clinical significance. However, estimation of PyV infection in healthy population is of importance as it can not only provide the baseline data for risk assessment of active infection but can also shed light on the molecular epidemiology of various virus species in different geographical areas. Diverse molecular techniques have been employed over the last few years for rapid and specific detection of BKPyV and JCPyV DNA in immunocompetent individuals. However, the utilization of Real-time PCR (qPCR) remained on the top because of its superior sensitivity and specificity towards the detection as well as measurements of the PyVs [24]. Nevertheless, molecular based studies have manifested contrasting results about the distribution of BKPyV and JCPyV in different geographical regions of the world [25]. Unfortunately, to the best of our knowledge, not even a single study about the prevalence and quantification of BKPyV and JCPyV in Pakistani population has so far been conducted. Keeping in view the high seropositivity rate of $\mathrm{BKPyV}$ and JCPyV across the world it is imperative to study the molecular epidemiology of these viruses in Pakistan. Herein we present the first ever report on quantitative prevalence of BKPyV and JCPyV in apparently healthy Pakistani population.

\section{Methods \\ Blood samples and subjects}

The study was approved by the Ethics Committee of School of Biological Sciences, University of the Punjab, Lahore, Pakistan. A total of 266 individuals (males $=183$, females $=83$ ) from different localities of Punjab province, aged 10-80 years, were selected randomly. All participating individuals were asked for their consent on a written proforma. All the selected donors were negative for HBV, HCV and HIV infection. The population under study was divided into three age groups; $\leq 25$ years (young age group), 26-50 years (middle age group) and $>51$ years (older age group) in order to check the variations in the prevalence of these viruses in different ages. The young age group comprised of 96 individuals while the rest of two groups included 85 individuals each. A total of $5 \mathrm{~mL}$ peripheral blood was collected from each individual in vacutainers having EDTA (Becton Dickinson, USA) and stored at $-20^{\circ} \mathrm{C}$ until further testing since long term storage of whole blood at $-20{ }^{\circ} \mathrm{C}$ does not affect the quality of DNA [26].

\section{DNA extraction and quality assay}

The DNA was extracted from $1 \mathrm{~mL}$ whole blood using salt precipitation method described elsewhere [27]. Briefly, $1 \mathrm{~mL}$ of whole blood from each sample was mixed with $1 \mathrm{~mL}$ Buffer A $(0.32 \mathrm{M}$ sucrose, $10 \mathrm{mMTrisCl}, 5 \mathrm{mM}$ $\mathrm{MgCl}_{2}$ and $0.75 \%$ Triton-X-100, $\mathrm{pH} 7.6$ ) and $1 \mathrm{~mL}$ of cold deionized water in sterile tubes followed by incubation on ice for 2-3 min. Tubes were centrifuged at $3500 \mathrm{rpm}$ for $15 \mathrm{~min}$ at room temperature. Obtained pellets were resuspended in $1 \mathrm{~mL}$ of Buffer $\mathrm{A}$ and $3 \mathrm{~mL}$ of water and centrifuged again at above mentioned conditions. Following centrifugation, pellets were resuspended in $3 \mathrm{~mL}$ of Buffer B (20 mMTris- $\mathrm{HCl}, 4 \mathrm{mM} \mathrm{Na}{ }_{2}$ EDTA and $100 \mathrm{mM} \mathrm{NaCl}$, 
$\mathrm{pH} 7.4)$ and $500 \mu \mathrm{L}$ of $10 \%$ SDS (10gm SDS in $100 \mathrm{~mL}$ water) by gentle vortexing. Mixtures were incubated at $55^{\circ} \mathrm{C}$ for $2 \mathrm{~h}$ by adding $10 \mu \mathrm{L}$ of refrigerated proteinase $\mathrm{K}$ solution $(20 \mathrm{mg} / \mathrm{mL})$. Following incubation, $3 \mathrm{~mL}$ of $5 \mathrm{M} \mathrm{NaCl}$ was added and samples were centrifuged at $4500 \mathrm{rpm}$ for $20 \mathrm{~min}$. The supernatants were collected into other tubes carefully and equal volume of ice cold isopropanol was added. Pellets were collected by following the centrifugion at $4500 \mathrm{rpm}$ for $20 \mathrm{~min}$ and washed with $70 \%$ ethanol. Finally pellets were suspended in $100 \mu \mathrm{L}$ of DNase/RNase free water and stored at $-20{ }^{\circ} \mathrm{C}$.

The quantity of DNA was measured by nanodrop (DeNovix DS-11 Spectrophotometer) and 260\280 ratios were confirmed. Quality of extracted DNA was assessed by gel electrophoresis. $\beta$-globin polymerase chain reaction was performed with all DNA specimens to check the suitability of the samples for PCR analysis and the absence of inhibitors in the reaction. The primers used to amplify a 268 bps region of $\beta$-globin genes were; forward primer 5' -CAACTTCATCCACGTTCACC-3' and reverse primer 5'-GAAGAGCCAAGGACAGGTAC-3' [28]. The reaction mixture of $25 \mu \mathrm{l}$ was prepared and the amplification profile was set in thermocycler (Eppendorf) for 10 min at $95{ }^{\circ} \mathrm{C}$ for activation of Taq DNA polymerase followed by 30 cycles of denaturation $\left(95^{\circ} \mathrm{C}\right.$ for $\left.30 \mathrm{~s}\right)$, annealing $\left(59{ }^{\circ} \mathrm{C}\right.$ for $\left.30 \mathrm{~s}\right)$ and extension $\left(72{ }^{\circ} \mathrm{C}\right.$ for $30 \mathrm{~s}$ ) and final extension at 72 for 10 mints.

\section{Positive controls and standard curves for BKPyV and JCPyV} The LT antigens of BKPyV (Dunlop strain) and JCPyV (MAD1 strain) cloned in pcDNA3 expression vector, were a kind gifted from Dr. Tommasino, International Agency for Research on Cancer, Lyon, France. These plasmids were used as positive controls for BKPyV and JCPyV standard curves preparation. The standard curves were plotted for each virus by using 10 -fold serial dilutions of positive control plasmids as described elsewhere [29]. Briefly, the mass of a single plasmid molecule was calculated first by using the following formula,

$$
\mathrm{m}=[\mathrm{n}]\left[1.096 \times 10^{-21} \mathrm{~g} / \mathrm{bp}\right]
$$

Where : $\mathrm{n}=$ Plasmid size $(\mathrm{bp})$ and $\mathrm{m}=$ mass

The mass of plasmid needed for the copy number of interest was calculated as below,

\section{Mass of plasmid DNA needed}

$=$ Copy No. of interest $\times$ mass of single plasmid

The concentration of plasmid DNA required to prepare the copy number of interest was calculated by dividing the mass plasmid DNA needed by the vol. to be pipetted into each reaction. The 10 fold serial dilutions from maximum copy number dilution $\left(10^{6}\right)$ to lowest copy number dilution $\left(10^{\circ}\right)$ were prepared. The input copy number range was selected from $10^{6}$ to $10^{\circ}$ in a way that $5 \mu \mathrm{L}$ of each standard dilution used in $20 \mu \mathrm{L}$ PCR reaction contained the desired copy number. These standard controlled dilutions were stored at $-20^{\circ} \mathrm{C}$ as aliquots until used.

\section{$L T$ antigen primers and cross reactivity}

The full length LT antigen sequences of BKPyV (Dunlop strain) and JCPyV (MAD1 strain) were retrieved from GenBank from accession code NC_001538 and NC_001699, respectively. These sequences were used to design primers for the amplification of the specific target gene Large $T$ antigen of $\mathrm{BKPyV}$ and JCPyV by using primer quest bioinformatics tool. A forward primer 5 '-AATATTATG CCCAGCACACATG-' 3 and reverse primer 5 '-CTTTC CCTCTGATCTACACCAG-'3 was used to amplify a 155 bps region of LT antigen of BKPyV. Likewise, a pair of forward primer $5^{\prime}$-AGAGTGTTGGGATCCTGTG TTTT-' 3 and reverse primer 5 '-TTGCAGGGCATTTT GTTTTTTAC-' 3 were used to amplify a 177 bps region of LT antigen of JCPyV. In order to check the cross reactivity of $\mathrm{BKPyV}$ and $\mathrm{JCPyV}$ primers, each primer set was subjected to standard PCR to amplify LT antigen target gene of both viruses by employing irrespective targets. Amplification profile was set as $10 \mathrm{~min}$ at $95{ }^{\circ} \mathrm{C}$ followed by 35 cycles of denaturation $\left(95^{\circ} \mathrm{C}\right.$ for $\left.30 \mathrm{~s}\right)$, annealing $\left(57^{\circ} \mathrm{C}\right.$ for $\left.1 \mathrm{~min}\right)$ and extension $\left(72{ }^{\circ} \mathrm{C}\right.$ for $\left.1 \mathrm{~min}\right)$ and final extension at ${ }^{\circ} \mathrm{C}$ for $10 \mathrm{~min}$.

\section{Real time PCR for the quantification of BKPyV and JCPyV DNA}

Fluorogenic quantitative real time PCR was carried out on PikoReal real time detection system (Thermo Fisher Scientific) to detect and quantify BKPyV and JCPyV viral loads. For each $20 \mu \mathrm{L}$ PCR reaction mixture, $10 \mu \mathrm{L}$ of maxima SYBR green qPCR 2X master mix (Thermo Fisher Scientific), 0.3 pmol of each BKPyV LT forward and reverse primer, $3.8 \mu \mathrm{L}$ sterile water and $5 \mu \mathrm{L}$ of $6 \mathrm{ng} / \mu \mathrm{L}$ DNA samples was used. For each sample, the real time PCR was performed in triplicate in 96 well plates. Each plate contained blood DNA samples, BKPyV standard controls $\left(10^{6}\right.$ to $10^{0}$ copy numbers) as well as water and empty pcDNA3 as negative control. Thermal cycling was initiated with a denaturation step of $95{ }^{\circ} \mathrm{C}$ for $10 \mathrm{~min}$. It was followed by 50 cycles of $95{ }^{\circ} \mathrm{C}$ for $30 \mathrm{~s}$ and $57^{\circ} \mathrm{C}$ for $30 \mathrm{~s}, 72{ }^{\circ} \mathrm{C}$ for $15 \mathrm{~s}$ and final extension at $72{ }^{\circ} \mathrm{C}$ for $5 \mathrm{~min}$. Melt curve analysis was included in real time PCR protocol. Following conditions were used for melt curve $55{ }^{\circ} \mathrm{C}$ to $95{ }^{\circ} \mathrm{C}$ : Increment $1{ }^{\circ} \mathrm{C}$ for $1 \mathrm{~min}$. Same protocol and reaction set up was repeated for JCPyV detection and quantification. Melt curve, melt peak and other data analysis was performed with PikoReal 2.2 software. The standard amplification curve of known quantity of DNA ( $L T$-BKPyV-pcDNA3 and LT-JCPyVpcDNA3) was used to determine the unknown amount of 
DNA in the test samples. The lower limit for the detection of BKPyV and JCPyV was $10^{\circ}$ and $10^{1}$ copies per reaction respectively. Some amplified PCR products were also checked and confirmed by agarose gel electrophoresis.

\section{Statistical analysis}

The statistical analysis was carried out using SPSS software package version 19 (IBM, NY). The data is presented as the Mean \pm SEM. The standard two sample $t$-test was used to test differences between the means. One way ANOVA is applied for testing of equivalence of the three age group averages, whereas the Chi-square test is applied for testing the equality of proportion. The $p$-values less than 0.05 were considered statistically significant and vice versa. MS EXCEL 2010 and SPSS 19 softwares were used for computational purpose.

\section{Results}

\section{Demographic characteristics of the studied human} population

A total of 266 blood samples of healthy individuals from different districts of Punjab region Pakistan, were collected for this study. Out of these, 68.8\% $(n=183)$ individuals were male and $31.2 \%(n=83)$ were females. These samples were divided into three age groups. The number of individuals in each age group along with mean and median ages is shown in Table 1.

\section{DNA isolation and evaluation of BKPyV and JCPyV $L T$ primers for cross reactivity}

Genomic DNA was extracted from $1 \mathrm{~mL}$ whole blood of each participant and subjected to gel electrophoresis and $\beta$-globin PCR for the assessment of DNA quality and integrity. All samples showed compact and brighter bands on $1 \%$ agarose gel showing high quality of DNA (Additional file 1: Figure S1A). The $\beta$-globin amplification products were also observed in all DNA samples showing that DNA is intact and suitable for any downstream application (Additional file 1: Figure S1B). Cross reactivity of primers for $L T$ antigens of both viruses were evaluated among BKPyV and JCPyV. Primer set of BKPyV LT antigen as well as JCPyV LT antigen amplified only their respective targets in each virus showing the specificity of primers for $\mathrm{BKPyV}$ and JCPyV, respectively. No cross reactivity was observed between the primers of BKPyV and JCPyV (Additional file 2: Figure S2).

Table 1 Demographics of the study participants

\begin{tabular}{lllrc}
\hline Age Groups & $\begin{array}{l}\text { Ages } \\
\text { (Years) }\end{array}$ & $\begin{array}{l}\text { Participants } \\
\mathrm{n}(\%)\end{array}$ & $\begin{array}{r}\text { Mean } \pm \text { S.D } \\
\text { Age (Years) }\end{array}$ & $\begin{array}{r}\text { Median } \pm \text { S.D } \\
\text { Age (Years) }\end{array}$ \\
\cline { 1 - 3 } Young age group & $\leq 25$ & $96(36.2 \%)$ & $21 \pm 2.17$ & $20 \pm 2.40$ \\
Middle age group & $26-50$ & $85(31.9 \%)$ & $36.21 \pm 7.70$ & $36 \pm 7.47$ \\
Old age group & $\geq 51$ & $85(31.9 \%)$ & $63.24 \pm 8.93$ & $61 \pm 8.81$ \\
\hline
\end{tabular}

Real-time PCR assay for the quantification of BKPyV and JCPyV viral loads

For detection and quantification of BKPyV and JCPyV viral load in blood samples by qPCR, standard curves were plotted for each virus by using 10 fold serial dilutions of $L T$-BKPyV-pcDNA3 and LT-JCPyV-pcDNA3 plasmids. The concentrations of these positive standards dilutions were adjusted between $10^{6}$ and $10^{\circ}$ copies. The $\mathrm{Ct}$ values for $\mathrm{BKPyV}$ positive control dilutions were in the range of 17-37 (Fig. 1a) while 15-34 for JCPyV positive control dilutions (Fig. 2a). Results of standard curves were further analyzed with PikoReal 2.2 software. Melt curves analysis manifested peak at 74 and $77{ }^{\circ} \mathrm{C}$ for BKPyV and JCPyV target genes respectively (Figs. $1 \mathrm{~b}$ and $2 b)$. The assay efficiency was calculated $110 \%$ with $\mathrm{R} 2=$ 0.98 for $L T$-BKPyV-pcDNA3 (Fig. 1c) while $109 \%$ with $\mathrm{R} 2=0.99$ for $L T$-JCPyV-pcDNA3 (Fig. 2c). The PCR product of each dilution was analyzed on agarose gel and bands of respective molecular weight with decreasing intensities from high to low dilution were observed for both BKPyV (Fig. 1d) and JCPyV (Fig. 2d).

The $30 \mathrm{ng}$ of DNA isolated from each blood sample was used in real time PCR reaction for the quantification of BKPyV and JCPyV. The positive samples showed comparable amplifications of LT antigen of $\mathrm{BKPyV}$ and JCPyV. Amplification cycles (Ct values) of positive samples were within range of standard curve $\mathrm{Ct}$ values of both BKPyV (Fig. 3a) and JCPyV (Fig. 4a). Notably, melt curves of positive samples were also specific for target genes (data not shown). The BKPyV and JCPyV positive samples with low $\mathrm{Ct}$ values were also positive on $2 \%$ agarose gel but samples with high $\mathrm{Ct}$ values did not appear in the agarose gel (Figs. 3b and 4b). Viral load in each positive sample was calculated by comparing its $\mathrm{Ct}$ value with $\mathrm{Ct}$ values of standard curve.

\section{The prevalence of BKPyV and JCPyV in different age groups of Pakistani Population}

Overall, the BKPyV DNA was detected in 27.1\% (72/266) individuals. The BKPyV prevalence was $51 \%$ (49/96), $18.8 \%(16 / 85)$, and $8.2 \%(7 / 85)$ in young, middle and elder age groups respectively, showing that the presence of BKPyV significantly varies $(p$-value $=0.0001)$ in each age group and BKPyV positivity ratio decreases with the increase in age (Fig. 5a). On the other hand, the JCPyV DNA was detected in $11.6 \%(31 / 266)$ of studied population. Contrary to $\mathrm{BKPyV}, \mathrm{JCPyV}$ prevalence was slightly higher in middle and elder age groups in comparison to the young age group. JCPyV positivity was $8.3 \%$ (8/96), $15.3 \%(13 / 85)$, and $11.8 \%(10 / 85)$ in young, middle and elder age groups respectively. The difference in term of JCPyV positive samples was statistically not significant ( $p$-value $=0.345)$ among different age groups (Fig. 5b). 


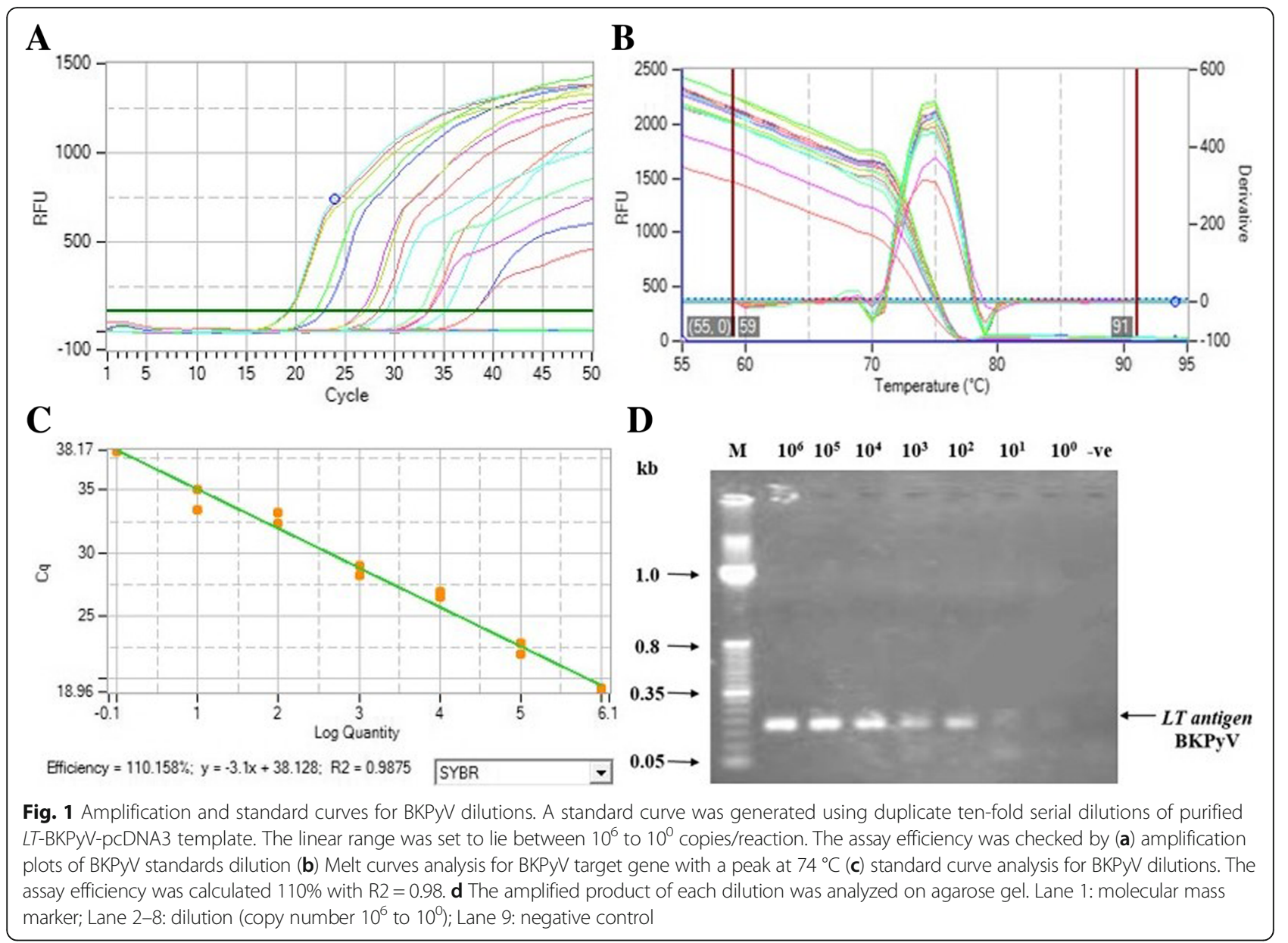

The BKPyV and JCPyV viral loads in individuals of different age groups from Pakistan

$\mathrm{BKPyV}$ and JCPyV viral copy numbers in the positive samples were also calculated by comparing the $\mathrm{Ct}$ values with $\mathrm{Ct}$ values of standard curve and expressed as log copy number per $\mathrm{mL}$. Age specific viral load was monitored and represented in the Box-whisker plots. Overall, the BKPyV viral load was within 5.08-7.5 log copies per $\mathrm{mL}$ of blood. Median log copies of BKPyV for young age group ( $\leq 25$ years) was $6.3 \log$ copies $/ \mathrm{mL}$ of blood while for middle and elder age group (26-50 years and $\geq$ 51 years) it was $5.9 \mathrm{log}$ and $6.1 \mathrm{log}$ copies per $\mathrm{mL}$ of blood. These results demonstrate that BKPyV viral load is $(p$-value $=0.477)$ (Fig. 6a). The JCPyV viral load was within 2.3-5.1 log copies per $\mathrm{mL}$ of blood. Viral load was maximum in eldest age group ( $\geq 51$ years) with median $3.6 \log$ copies per $\mathrm{mL}$ of blood. In other two age groups; $\leq 25$ years and $26-50$ years, median copy number was similar $3.2 \mathrm{log}$. Statistically, the JCPyV viral load does not differ in studied age groups $(P$-Value $=0.325)$ (Fig. 6b). The prevalence and viral loads of BKPyV and JCPyV in all age groups along with mean and median are mentioned in Table 2.

\section{Overall comparison between BKPyV and JCPyV in term of prevalence and viral load}

Altogether, prevalence of BKPyV was compared with JCPyV in the studied population. It was concluded that BKPyV prevalence $(27.1 \%)$ was significantly $(p$ value $=0.00012)$ high in comparison to JCPyV (11.6\%) in Pakistani population (Fig. 7a). Similarly, BKPyV and JCPyV viral load was compared and found that BKPyV viral load (5.08-7.5 log copies per $\mathrm{mL}$ of the blood) was significantly higher than JCPyV load (2.34-5.17 log copies per $\mathrm{mL}$ of blood) $(p$-value $=0.00042)($ Fig. $7 \mathrm{~b})$.

\section{Discussion}

Human polyomaviruses are circular double stranded DNA viruses which belong to Polyomaviridae family of viruses [25]. Out of 13 human polyomaviruses, only BKPyV, JCPyV, MCPyV and TSPyV have been directly linked with clinical ailments [30]. We particularly focused on BKPyV and JCPyV due to their association with specific human diseases: polyomavirus associated nephropathy and progressive multifocal leukoencephalopathy respectively [31]. The frequencies of these viruses vary in different geographical regions and population, in different biological 


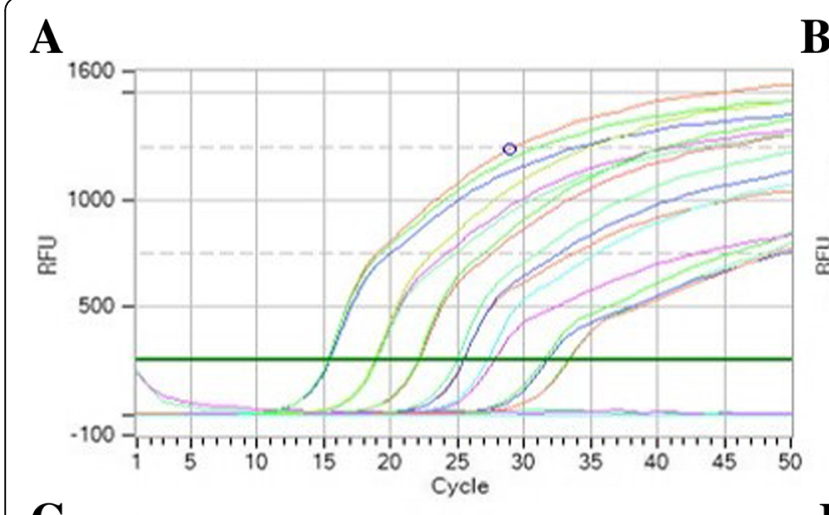

B

C
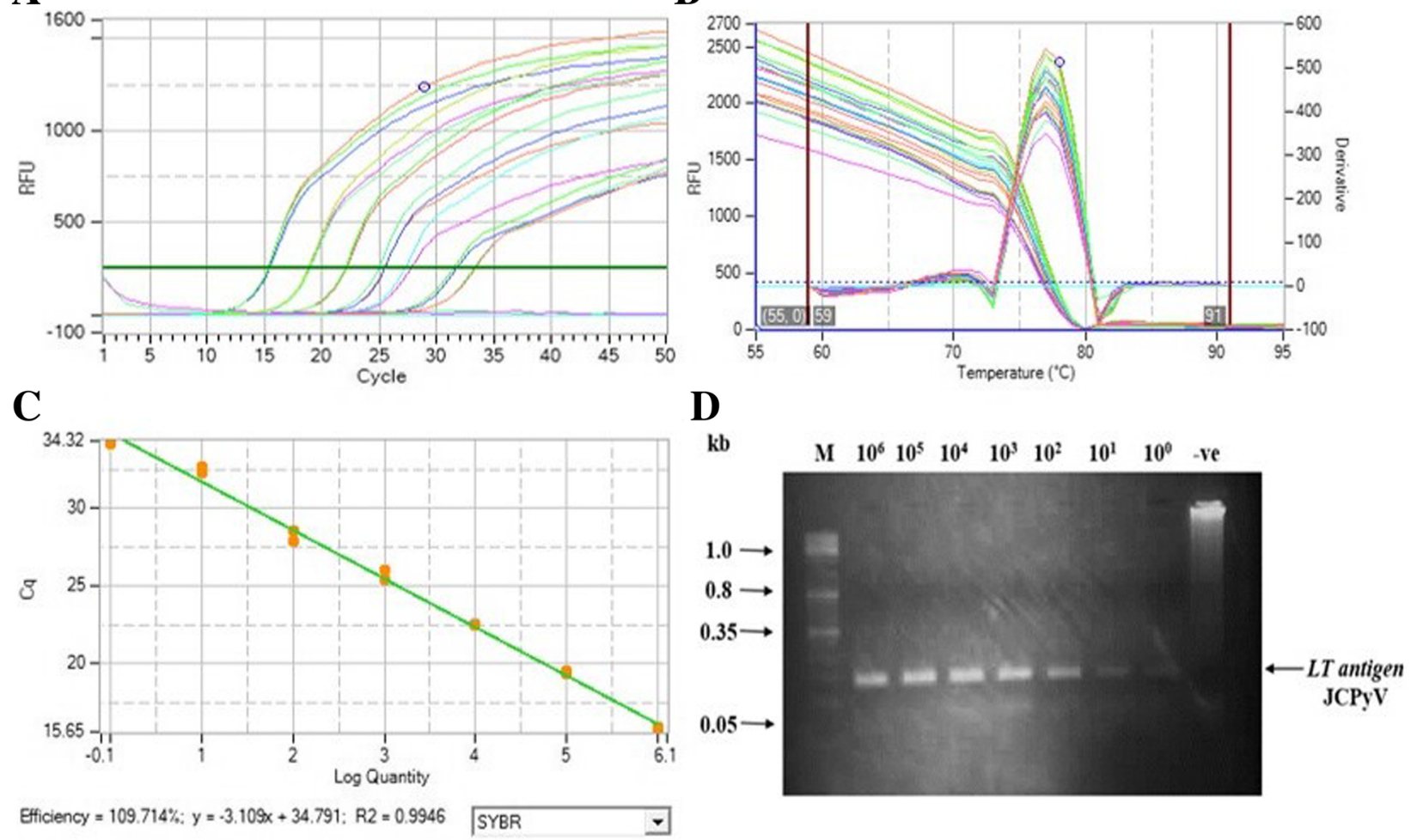

Fig. 2 Amplification and standard curves for JCPyV dilutions. A standard curve was generated using duplicate ten-fold serial dilutions of purified LT-JCPyV-pcDNA3 template. The linear range was set to lie between $10^{6}$ to $10^{\circ}$ copies/reaction. The assay efficiency was checked by (a) amplification plots of JCPyV standards dilution (b) Melt curves analysis for JCPyV target gene with a peak at $77^{\circ} \mathrm{C}$ (c) standard curve analysis for JCPyV dilutions. The assay efficiency was calculated $109 \%$ with R2 $=0.99$. $\mathbf{d}$ The amplified product of each dilution was analyzed on agarose gel. Lane 1: molecular mass marker; Lane 2-8: dilution (copy number $10^{6}$ to $10^{\circ}$ ); Lane 9: negative control

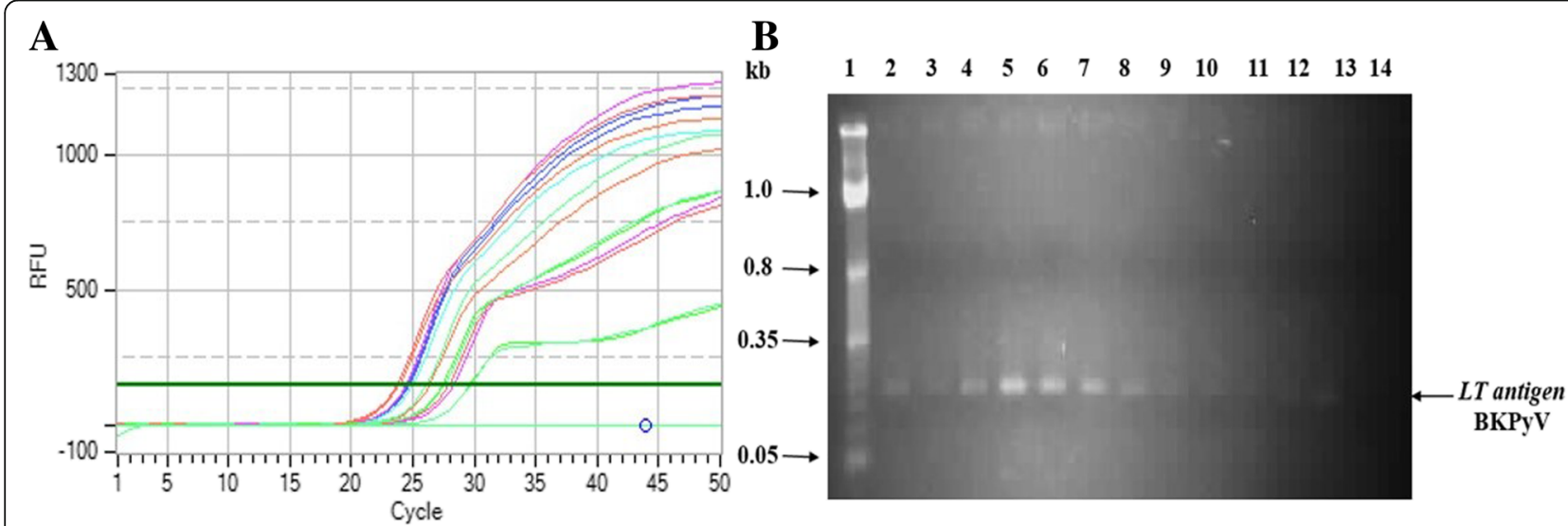

Fig. 3 Real time assay for the quantification of BKPyV in healthy blood samples. The qPCR was performed by using $30 \mathrm{ng}$ DNA of each sample and virus copy number was determined by comparing with standard curve of known BKPyV dilutions. a Amplification plots of some representative positive samples for BKPyV. $\mathbf{b}$ The amplified product of these representative positive samples was analyzed by gel electrophoresis. The amplified product showed band of 151 bps corresponding to BKPyV LT. Lane 1: molecular mass marker; Lane 2-13: representative positive samples for BKPyV; Lane 14: negative control 


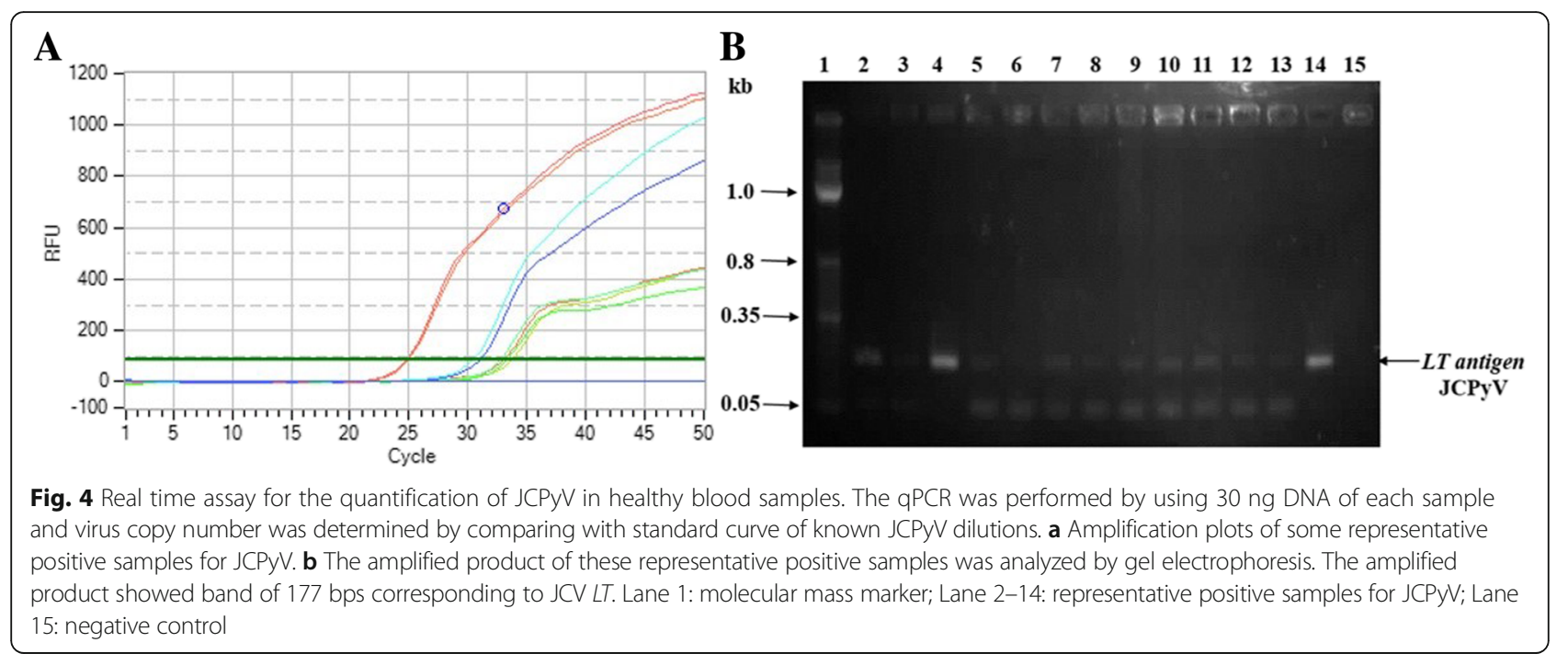

samples and even within a same population due to the choice of technique used for the detection [32-34]. In Pakistan, unfortunately not even a single report, to the best of our knowledge is available about the prevalence of these hazardous viruses. Our study being first ever report on the distribution of polyomaviruses in Pakistan not only describes the prevalence of these viruses but also quantified viral load in positive samples. A total of 266 apparently healthy individuals were recruited in this study and these individuals were divided in three age groups; $\leq 25$ years, $26-50$ years and $\geq 51$ years. The DNA was extracted from whole peripheral blood and used for the detection and quantification of BKPyV and JCPyV by real time PCR. The results described the overall prevalence of $\mathrm{BKPyV}$ and JCPyV as 27.1 and $11.6 \%$ respectively. The overall viral load was in the range of 5.08-7.5 $\log$ and 2.34-5.17 $\log$ for $\mathrm{BKPyV}$ and JCPyV respectively.
Previously, the seroprevalence of these viruses was studied mainly and BKPyV prevalence was reported to be $55-85 \%$ [35] and JCPyV to be $50-80 \%$ [36]. Likewise, molecular detection of these viruses in both immunosuppressed and immunocompetent individuals has also been reported in some studies where serum/plasma or urine samples were targeted for BKPyV and JCPyV detection. These studies reported the urinary shedding of BKPyV and JCPyV in healthy population 7 and $19 \%$ respectively [37]. Discordant data regarding the prevalence of these viruses in healthy individuals has previously been published. By and large, blood polyomavirus positivity has varied from 0 to $90 \%$ in healthy immunocompetent individuals [17]. Similarly, different studies have described variable range of $\mathrm{BKPyV}$ and JCPyV viral loads in healthy individuals from different parts of the world $[18,37-40]$. These viruses were less frequent overall in
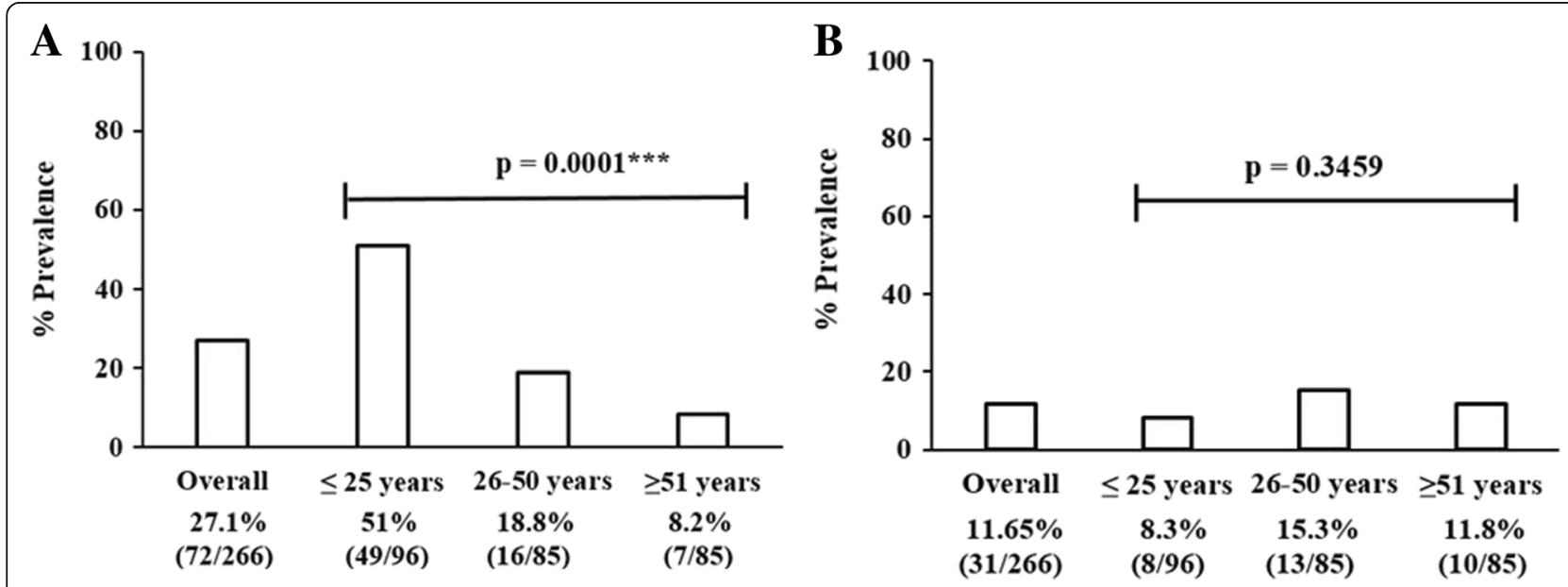

Fig. 5 The prevalence of BKPyV and JCPyV in the blood of healthy Pakistani population. Overall 266 blood samples from healthy individuals of Pakistan were analyzed for the presence of BKPyV and JCPyV. a The bar graph shows the overall and age-wise prevalence of BKPyV in the studied population. $\mathbf{b}$ The bar graph shows the overall and age wise prevalence of JCPyV in the studied population 


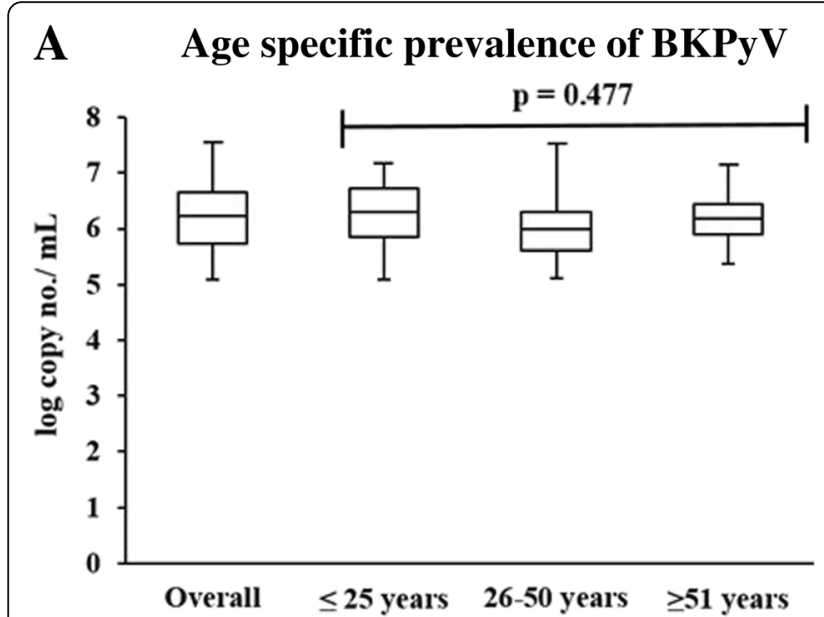

B Age specific prevalence of JCPyV

Fig. 6 The age specific prevalence and copy number of BKPyV and JCPyV in the blood of healthy Pakistani population. Overall 266 blood samples from healthy individuals of Pakistan were analyzed for the presence of BKPyV and JCPyV. The virus copy numbers were also calculated for positive samples. The virus load in the positive samples was expressed as log copy number $/ \mathrm{mL}$. a Box-whisker plots show the BKPyV positive samples and range of virus copy number in the positive samples of overall and three age groups ( $\leq 25$ years, $26-50$ years and $\geq 51$ years). b Box-whisker plots show the JCPyV positive samples and range of virus copy number in the positive samples of overall and three age groups $(\leq 25$ years, $26-50$ years and $\geq 51$ years)

urine and/or serum/plasma of healthy individuals [17]. The low viral load in these body fluids could be explained by the fact that both of these viruses remain latent in healthy population and viruria or viremia increase only as a consequence of their reactivation [20]. In contrast to most of the previous studies, our protocol uses DNA extracted from peripheral whole blood instead of serum or plasma. This modification in already established serum/plasma based protocols not only simplifies the procedure but is also of great importance because recent reports suggest that PBMC, leukocytes and lymphocytes may serve as a site of latency for these viruses in healthy population $[17,41]$. Thus, future studies aiming to verify this hypothesis may benefit from our suggested method.

Previous studies have reported variable molecular prevalence rates in different populations. In Italy, for instance, the molecular prevalence of $\mathrm{BKPyV}$ was reported $22 \%$ in lymphocytes which is comparable to our results that is $27 \%(72 / 266)$ overall prevalence [17]. While in a cohort of Chinese population $42.1 \%$ BKPyV prevalence in peripheral blood leukocytes was reported [19]. In our results, the frequency of $\mathrm{BKPyV}$ was maximum in the youngest age group ( $\leq 25$ years) $51 \%(49 / 96)$ and decreased to $8.2 \%$ $(7 / 85)$ in the eldest age group ( $\geq 51$ year). Contradicting studies are available regarding age-wise prevalence of BKPyV. A study on age specific molecular prevalence of BKPyV in Germany showed that increasing age has no significant effect on the molecular prevalence of polyomavirus in peripheral blood [18]. However, a study targeting European population reported seroprevalence rates going down from $80 \%$ in young adults to $55 \%$ in older age group [42]. These results appear to agree with our observation. Other studies have also reported similar trends in age specific seroprevalence studies of BKPyV [20, 43, 44].

In the present study JCPyV DNA was detected only in $11.6 \%(31 / 266)$ participant that is comparable with earlier reports from various Asian populations, for instance $8 \%$ in healthy Chinese population and $14 \%$ in healthy tribal Indian population $[17,38]$. A peculiar age group specific trend in JCPyV infection, different from BKPyV, was observed. Rate of positivity for JCPyV first increased from young to middle age group before declining again in older age group. The positivity rate in old age group though less

Table 2 Age specific viral status in blood samples evaluated for BKPyV and JCPyV

\begin{tabular}{|c|c|c|c|c|c|c|c|}
\hline \multirow{2}{*}{$\begin{array}{l}\text { Age Groups } \\
\text { (Years) }\end{array}$} & \multicolumn{3}{|l|}{ BKPyV } & \multicolumn{3}{|l|}{ JCPyV } & \multirow{2}{*}{$\begin{array}{l}\text { BKPyV \& JCPyV Co-infection } \\
\text { Positive sample } \%(n)\end{array}$} \\
\hline & $\begin{array}{l}\text { Positive } \\
\text { sample \% (n) }\end{array}$ & $\begin{array}{l}\text { Viral copy no. } \\
\text { (log/mL of blood) }\end{array}$ & Mean \pm S.D & Positive sample \% (n) & $\begin{array}{l}\text { Viral copy no. } \\
\text { (log/mL of blood) }\end{array}$ & Mean \pm S.D & \\
\hline$\leq 25$ years & $51.0 \%(49 / 96)$ & $5.08-7.14$ & $6.24 \pm 0.56$ & $8.3 \%(8 / 96)$ & $3.25-4.35$ & $3.70 \pm 0.37$ & $0.7 \%(2 / 266)$ \\
\hline 26-50 years & $18.8 \%(16 / 85)$ & $5.10-7.5$ & $6.04 \pm 0.63$ & $15.3 \%(13 / 85)$ & $3.02-4.28$ & $3.44 \pm 0.44$ & \\
\hline$\geq 51$ years & $8.2 \%(7 / 85)$ & $5.37-7.15$ & $6.19 \pm 0.56$ & $11.8 \%(10 / 85)$ & $2.34-5.17$ & $3.32 \pm 0.82$ & \\
\hline Overall & $27.1 \%(72 / 266)$ & $5.08-7.5$ & $6.19 \pm 0.57$ & $11.65 \%(31 / 266)$ & $2.34-5.17$ & $3.47 \pm 0.52$ & \\
\hline
\end{tabular}




\section{A \\ BKPyV vs JCPyV prevalence}

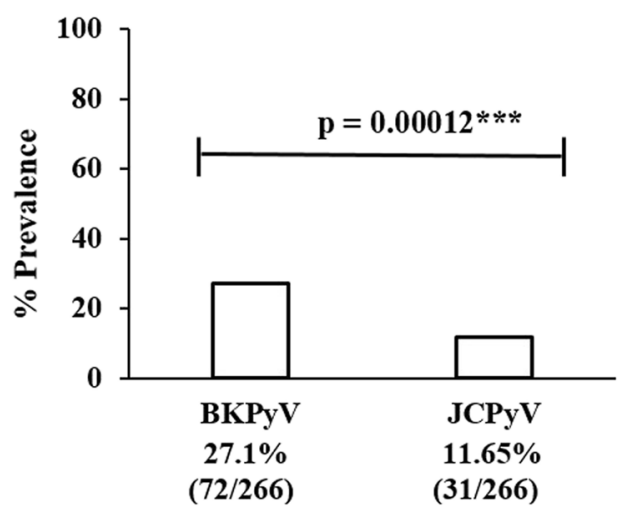

B

\section{BKPyV vs JCPyV viral loads}

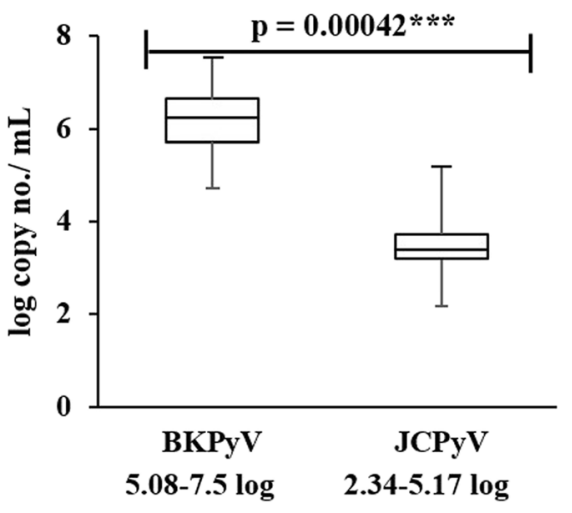

Fig. 7 A comparison of the prevalence as well as viral between BKPyV and JCPyV in the blood of healthy Pakistani population. Overall 266 blood samples from healthy individuals of Pakistan were analyzed for the presence of BKPyV and JCPyV. a The bar graph shows the overall difference among the prevalence of BKPyV and JCPyV in the studied population. $\mathbf{b}$ Box-whisker plots compares the BKPyV and JCPyV range of virus copy number in the positive samples of overall population

than middle age group, nonetheless remained higher as compared to young age group. In the youngest age group ( $\leq 25$ years), the frequency of JCPyV was $8.3 \%$ (8/96) which reached up to maximum in middle age groups (26-50 years) to $15.3 \%(13 / 85)$, and then in eldest age groups ( $\geq 51$ years) decreased to, $11.8 \%(10 / 85)$. However, this difference in JCPyV frequency was not significant statistically $(p=0.345)$. Contradictory findings have been reported previously from different parts of the world regarding the age group specific prevalence of JCPyV. For example, Delbue et al. found that age has no significant effect on the molecular prevalence of polyomaviruses [18]. Contrary to that, Sadeghi et al. reported that seroprevalence of JCPyV in Australian population increases from 60 to $68 \%$ in middle-ages and then decrease to $64 \%$ in oldest ages [45]. Although a similar trend was noticed in our study, rate of JCPyV infection in our target population was much lower than the Australian cohort.

We also quantified the viral loads in the positive samples and expressed as log copies per $\mathrm{mL}$ of blood. The viral loads calculated in our study were in the range of 5-7.5 and 2.34-5.17 log copies per $\mathrm{mL}$ of blood for BKPyV and JCPyV respectively, without any significant difference in each age group. The high viral load calculated in our study could be due to the use of whole blood instead of serum/plasma because whole blood contains reservoirs of latent BKPyV and JCPyV. This hypothesis is supported by Delbue et al.'s study where the researchers reported high viral load of both BKPyV $(7 \times$ $10^{3}$ copies $\left./ \mu \mathrm{g}\right)$ and $\mathrm{JCPyV}\left(2 \times 10^{4}\right.$ copies $\left./ \mu \mathrm{g}\right)$ using whole peripheral blood of immunocompetent individuals similar to the present report [18]. The viral load in this study was described as "copies/ $\mu \mathrm{g}$ " which becomes equivalent to our study once converted into log copies per $\mathrm{ml}$.

The prevalence of BKPyV and JCPyV in the immunocompetent individuals in our study is higher than Europe and USA but it is less than already reported in Asian countries such as China and India. For example, $\mathrm{Gu}$ et al. reported overall prevalence of BKPyV DNA in Peripheral blood leukocytes (PBLs) of healthy adult individuals in China as $42.1 \%$ [19], which is considerably higher than the present report. Similarly, viral load described in our study is lower than already described in India. Chattaraj et al. reported high viral load of JCPyV $\left(7.77 \times 10^{5}\right.$ copies $\left./ \mathrm{ml}\right)$ in the blood of healthy individuals from Indian tribes [38], higher than our report. Based on the very few reports that are available from Asia, it may be hypothesized that incidence and viral load of these ployomaviruses in this part of the world is higher than other regions. However, detailed studies may be required to substantiate this claim.

It is well established that nutritional deficiency might result in immunodeficiency which in turn can augment the receptiveness towards different infections [46]. The majority of population in both India and Pakistan cannot meet their dietary requirements due to poor socio economical conditions. The nutritional deficiencies could also explain the high viral load particularly in this part of the world. However, more studies will be needed to understand the contribution of nutritional deficiencies in immunosuppression among South Asian population.

In comparison to the $\mathrm{JCPyV}$ in our findings, BKPyV had higher viral load and molecular prevalence in healthy population of Pakistan. These significant differences in the prevalence and viral load of these viruses can be explained due to their specific virus-host interaction 
and pathogenesis. We also investigated the probability of co-infection with both of the species and found that only $0.7 \%$ of the individuals included in our study had a co-infection of BKPyV and JCPyV. Similar co-infection rates (1\%) have previously been reported by Egli et al. in Switzerland [43].

In this study, we successfully demonstrated detection of both JCPyV and BKPyV species in peripheral blood samples of apparently healthy Pakistani individuals, therefore our study highlights the utility of blood as suitable sample type for polyomavirus surveillance studies. Moreover, sensitive and specific molecular detection method used in our study also lends credence to the hypothesis that PBMCs can serve as sites of latency for polyomaviruses. However, due to the unavailability of urine samples in sufficient numbers and quality suitable for molecular detection of virus, this important analysis could not be included in present study. Nonetheless, our report has provided baseline data upon which further studies can be designed for better estimation of BKPyV and JCPyV prevalence in general Pakistani population.

\section{Conclusion}

The present study provides an important baseline data on prevalence and viral load of BKPyV and JCPyV in the blood of apparently healthy Pakistan population. The BKPyV prevalence $27.1 \%(72 / 266)$ was higher than JCPyV 11.6\% (31/266). The prevalence of BKPyV significantly decreased with increase in age while JCPyV positivity rate slightly increased with increasing age. Likewise, the viral load of $\mathrm{BKPyV}$ was significantly higher than JCPyV. However, both BKPyV and JCPyV viral load was not correlated with the individual ages. Conclusively, this study on polyomaviruses in Pakistan manifested the existence of both BKPyV and JCPyV in the blood of apparently healthy Pakistani population.

\section{Additional files}

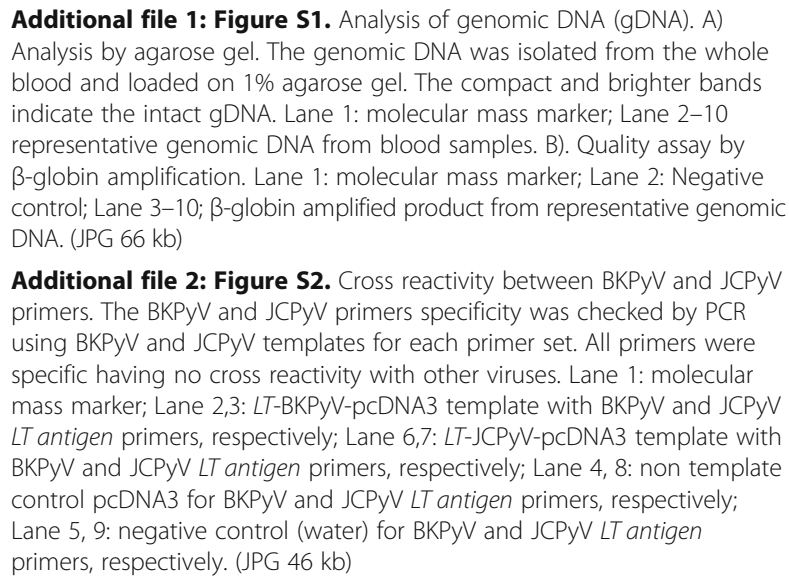

Additional file 2: Figure S2. Cross reactivity between BKPyV and JCPyV primers. The BKPyV and JCPyV primers specificity was checked by PCR using BKPyV and JCPyV templates for each primer set. All primers were specific having no cross reactivity with other viruses. Lane 1: molecular mass marker; Lane 2,3: LT-BKPyV-pcDNA3 template with BKPyV and JCPyV LT antigen primers, respectively; Lane 6,7: LT-JCPyV-pcDNA3 template with BKPyV and JCPyV LT antigen primers, respectively; Lane 4, 8: non template control pCDNA3 for BKPYV and JCPyV LT antigen primers, respectively; Lane 5, 9: negative control (water) for BKPyV and JCPyV LT antigen primers, respectively. (JPG $46 \mathrm{~kb}$ )

\section{Abbreviations}

BKPyV: BK polyomavirus; JCPyV: JC polyomavirus; LT antigen: Large tumor antigen; NCCR: Non coding control region; PBMCs: Peripheral blood mononuclear cells; PyV: Polyomavirus; qPCR: Real time PCR; ST antigen: Small tumor antigen; VP: Viral capsid protein

\section{Acknowledgement}

We acknowledge Dr. Massimo Tomassino team for the kind provision of BKPyV and JCPyV plasmids. We are sincerely thankful to Mr. ljaz Ahmed and Dr. Bilal Aslam for helping us in blood samples collection.

\section{Funding}

The funding and other research facilities for the accomplishment of this research work were provided by School of Biological Sciences, University of the Punjab Lahore, Pakistan.

\section{Authors' contributions}

NS conceived the idea and designed experiments. AP and MIA collected samples. IH and FT performed experiments and analyzed data. MR performed statistical analysis. MU critically reviewed the article. All authors contributed to article's writings and approved the final manuscripts.

\section{Competing interest}

The authors declare that they have no competing interests.

\section{Ethics approval and consent to participate}

The study was approved by the Ethics Committee of School of Biological Sciences, University of the Punjab, Lahore, Pakistan. All participating individuals were asked for their consent on a written proforma.

\section{Publisher's Note}

Springer Nature remains neutral with regard to jurisdictional claims in published maps and institutional affiliations.

\section{Author details}

${ }^{1}$ School of Biological Sciences, University of the Punjab, Lahore, Pakistan. ${ }^{2}$ Department of Zoology, University of the Punjab, Lahore, Pakistan. ${ }^{3}$ National Institute for Biotechnology \& Genetic Engineering, Faisalabad, Pakistan.

${ }^{4}$ Department of Mathematics and Statistics, Virtual University of Pakistan, Lahore, Pakistan. ${ }^{5}$ Institute of Microbiology, University of Agriculture, Faisalabad, Pakistan.

Received: 16 February 2017 Accepted: 19 April 2017

Published online: 24 April 2017

\section{References}

1. Gardner S, Field A, Coleman D, Hulme B. New human papovavirus (BK) isolated from urine after renal transplantation. Lancet. 1971;297(7712):1253-7.

2. Padgett B, Zurhein G, Walker D, Eckroade R, Dessel B. Cultivation of papova-like virus from human brain with progressive multifocal leucoencephalopathy. Lancet. 1971;297(7712):1257-60.

3. Ramos E, Drachenberg CB, Wali R, Hirsch HH. The decade of polyomavirus BKassociated nephropathy: state of affairs. Transplantation. 2009;87(5):621-30.

4. White MK, Khalili K. Pathogenesis of progressive multifocal leukoencephalopathy revisited. J Infect Dis. 2011;203(5):578-86. doi:https:// doi.org/10.1093/infdis/jiq097

5. Abend JR, Jiang M, Imperiale MJ. BK virus and human cancer: innocent until proven guilty. Semin Cancer Biol. 2009;19(4):252-60. doi:http://doi.org/10. 1016/j.semcancer.2009.02.004

6. Berger JR, Houff SA, Major EO. Monoclonal antibodies and progressive multifocal leukoencephalopathy. MAbs. 2009;1(6):583-9.

7. Dalianis T, Hirsch HH. Human polyomaviruses in disease and cancer. Virol. 2013;437(2):63-72.

8. Bollag B, Kilpatrick LH, Tyagarajan SK, Tevethia MJ, Frisque RJ. JC virus T' 135 $T^{\prime} 136$ and $T^{\prime} 165$ proteins interact with cellular p107 and p130 in vivo and influence viral transformation potential. J Neurovirol. 2006;12(6):428-42.

9. Abend JR, Joseph AE, Das D, Campbell-Cecen DB, Imperiale MJ. A truncated T antigen expressed from an alternatively spliced BK virus early mRNA. J Gen Virol. 2009b; 90(5):238-45. 
10. Weitschek E, Presti AL, Drovandi G, Felici G, Ciccozzi M, Ciotti M, Bertolazzi P. Human polyomaviruses identification by logic mining techniques. Virol J. 2012;9(1):58

11. Knowles WA. Discovery and epidemiology of the human polyomaviruses BK virus (BKV) and JC virus (JCV). In: Polyomaviruses and human diseases. New York: Springer; 2006. p. 19-45.

12. De Gascun CF, Carr MJ. Human polyomavirus reactivation: disease pathogenesis and treatment approaches. Clin Dev Immunol. 2013;2013. doi: http://dx.doi.org/10.1155/2013/373579

13. Cook L. Polyomaviruses. Microbiol Spect. 2016;4(4):DMIH2-0010-2015; doi:10. 1128/microbiolspec.DMIH2-0010-2015.

14. Eash S, Tavares R, Stopa EG, Robbins SH, Brossay L, Atwood WJ. Differential distribution of the JC virus receptor-type sialic acid in normal human tissues. Am J Pathol. 2004;164(2):419-28.

15. Dugan AS, Gasparovic ML, Atwood WJ. Direct correlation between sialic acid binding and infection of cells by two human polyomaviruses (JC virus and BK virus). J Virol. 2008;82(5):2560-4.

16. Chatterjee M, Weyandt TB, Frisque RJ. Identification of archetypeand rearranged forms of BK virus in leukocytes from healthy individuals. J Med Virol. 2000;60:353-62.

17. Dolei A, Pietropaolo V, Gomes E, Di Taranto C, Ziccheddu M, Spanu MA, et al. Polyomavirus persistence in lymphocytes: prevalence in lymphocytes from blood donors and healthy personnel of a blood transfusion centre. J Gen Virol. 2000;81(8):1967-73.

18. Delbue S, Tremolada S, Elia F, Carloni C, Amico S, Tavazzi E, et al. Lymphotropic polyomavirus is detected in peripheral blood from immunocompromised and healthy subjects. J Clin Virol. 2010;47(2):156-60.

19. Gu ZY, Li Q, Si YL, Li X, Hao HJ, Song HJ. Prevalence of BK virus and JC virus in peripheral blood leukocytes and normal arterial walls in healthy individuals in China. J Med Virol. 2003;70(4):600-5.

20. Bennett SM, Broekema NM, Imperiale MJ. BK polyomavirus: emerging pathogen. Microbes Infect. 2012;14(9):672-83.

21. Ashok A, Atwood WJ. Virus receptors and tropism. In: Polyomaviruses and Human Diseases. New York: Springer; 2006. p. 60-72.

22. Bloomgren G, Richman S, Hotermans C, Subramanyam M, Goelz S, Natarajan $A$, et al. Risk of natalizumab-associated progressive multifocal leukoencephalopathy. N Engl J Med. 2012;366(20):1870-80.

23. Kean JM, Rao S, Wang M, Garcea RL. Seroepidemiology of human polyomaviruses. PLoS Pathog. 2009:5(3):e1000363.

24. Iwaki KK, Qazi SH, Garcia-Gomez J, Zeng D, Matsuda Y, Matsuda K, et al. Development of a real-time quantitative PCR assay for detection of a stable genomic region of BK virus. Virol J. 2010;7(1):295

25. DeCaprio JA, Garcea RL. A cornucopia of human polyomaviruses. Nat Rev Microbiol. 2013;11(4):264-76.

26. Di Pietro F, Ortenzi F, Tilio M, Concetti F, Napolioni V. Genomic DNA extraction from whole blood stored from 15 -to 30 -years at $-20^{\circ} \mathrm{C}$ by rapid phenol-chloroform protocol: A useful tool for genetic epidemiology studies. Mol Cell Probes. 2011;25(1):44-8.

27. Gaaib JN, Nassief AF, Al-Assi A. Simple salting-out method for genomic DNA extraction from whole blood. Tikrit J Pure Sci. 2011;16(2):1813-662.

28. Marchetti S, Graffeo R, Siddu A, Santangelo R, Ciotti M, Picardi A, et al. BK virus DNA detection by real-time polymerase chain reaction in clinical specimens. Microbiologica. 2007;30(2):119-26.

29. McNees AL, White ZS, Zanwar P, Vilchez RA, Butel JS. Specific and quantitative detection of human polyomaviruses BKV, JCV, and SV40 by real time PCR. J Clin Virol. 2005;34(1):52-62.

30. Feltkamp MC, Kazem S, van der Meijden E, Lauber C, Gorbalenya AE. From Stockholm to Malawi: recent developments in studying human polyomaviruses. J Gen Virol. 2013;94(3):482-96.

31. Java A, Cheng X, Brennan DC. Polyomavirus infections of humans. Wiley: eLS. 2012. doi:10.1002/9780470015902.a0023619.

32. Gossai A, Waterboer T, Nelson HH, Michel A, Willhauck-Fleckenstein M, Farzan SF, Hoen AG, Christensen BC, Kelsey KT, Marsit CJ, Pawlita M. Seroepidemiology of human polyomaviruses in a US population. Am J Epidemiol. 2015;183(1):61-69. doi:https://doi.org/10.1093/aje/kwv155

33. Ling PD, Lednicky JA, Keitel WA, Poston DG, White ZS, Peng R, et al. The dynamics of herpesvirus and polyomavirus reactivation and shedding in healthy adults: a 14-month longitudinal study. J Infect Dis. 2003;187(10): 1571-80.
34. Zhong S, Zheng HY, Suzuki M, Chen Q, Ikegaya H, Aoki N, et al. Age-related urinary excretion of BK polyomavirus by nonimmunocompromised individuals. J Clin Microbiol. 2007;45(1):193-8.

35. White MK, Gordon J, Khalili K. The rapidly expanding family of human polyomaviruses: recent developments in understanding their life cycle and role in human pathology. PLoS Pathog. 2013;9(3):e1003206.

36. Boothpur R, Brennan DC. Human polyoma viruses and disease with emphasis on clinical BK and JC. J Clin Virol. 2010;47(4):306-12.

37. Husseiny Ml, Anastasi B, Singer J, Lacey SF. A comparative study of Merkel cell, BK and JC polyomavirus infections in renal transplant recipients and healthy subjects. J Clin Virol. 2010;49(2):137-40.

38. Chattaraj S, Bera NK, Dutta C, Bhattacharjee S. Quantification of human polyomavirus JC virus load in urine and blood samples of healthy tribal populations of North-Eastern part of West Bengal, India. Indian J Med Microbiol. 2015:33(4):491.

39. Matos A, Duque V, Beato S, da Silva JP, Major E, Meliço-Silvestre A. Characterization of JC human polyomavirus infection in a Portuguese population. J Med Virol. 2010;82:494-504. 17.

40. Chehadeh W, Kurien SS, Nampoory MR. Molecular characterization of BK and JC viruses circulating among potential kidney donors in Kuwait. Biomed Res Int. 2013;2013:683464.

41. Mertz KD, Junt T, Schmid M, Pfaltz M, Kempf W. Inflammatory monocytes are a reservoir for Merkel cell polyomavirus. J Invest Dermatol. 2010;130(4) $1146-51$.

42. Viscidi RP, Rollison DE, Sondak VK, Silver B, Messina JL, Giuliano AR, et al. Age-specific seroprevalence of Merkel cell polyomavirus, BK virus, and JC virus. Clin Vaccine Immunol. 2011;18(10):1737-43.

43. Egli A, Infanti L, Dumoulin A, Buser A, Samaridis J, Stebler C, et al. Prevalence of polyomavirus BK and JC infection and replication in 400 healthy blood donors. J Infect Dis. 2009;199(6):837-46.

44. Antonsson A, Green AC, Mallitt KA, O'Rourke PK, Pawlita M, Waterboer T, Neale RE. Prevalence and stability of antibodies to the BK and JC polyomaviruses: a long-term longitudinal study of Australians. J Gen Virol. 2010;91(7):1849-53.

45. Sadeghi F, Salehi-Vaziri M, Ghodsi SM, Alizadeh A, Bokharaei-Salim F, Saroukalaei ST, et al. Prevalence of JC polyomavirus large T antigen sequences among Iranian patients with central nervous system tumors. Arch Virol. 2015;160(1):61-8.

46. Harbige LS. Nutrition and immunity with emphasis on infection and autoimmune disease. Nutr Health. 1996:10:285-312

\section{Submit your next manuscript to BioMed Central and we will help you at every step:}

- We accept pre-submission inquiries

- Our selector tool helps you to find the most relevant journal

- We provide round the clock customer support

- Convenient online submission

- Thorough peer review

- Inclusion in PubMed and all major indexing services

- Maximum visibility for your research

Submit your manuscript at www.biomedcentral.com/submit 